UDC 615.1:37.014.54:378.4:659.4.012:338

DOI: $10.15587 / 2519-4852.2021 .248050$

\title{
RESULTS OF PUBLIC ASSESSMENT OF INFLUENCE FACTORS ON THE FORMATION OF THE BRAND OF THE INSTITUTION OF HIGHER EDUCATION IN THE PHARMACEUTICAL DIRECTION
}

\author{
Alla Kotvitska, Alina Volkova, Olena Yakovlieva \\ The aim of the article is to study the attitude of target audiences to the brand of a higher education institution, \\ taking into account the specifics of the educational services provided to them and the specifics of the educational \\ services market.
}

Methods of the research: theoretical (analysis and synthesis of scientific literature and normative sources, generalization, analytical, comparative and logical), empirical (descriptions, comparison, questionnaires, mathematical and statistical).

Materials: questionnaires of respondents, which were applicants, students, alumni and employees of NUPh. Results of the research. According to students, the most significant factors are positive reviews about HEI (14\% of respondents), the quality of educational services and the involvement of well-known scientists and practitioners (12\% each), the presence of scientific schools, traditions and the active participation of the institution in public life (11\% each factor). For applicants, an important place is occupied by the state status of a higher education institution, positive reviews about it and high quality of educational services (13\% for each factor). The advantages that graduates of the prestigious HEI have after graduation are a high level of theoretical knowledge $(89 \%$ of respondents) and practical skills (85\%), a high level of competitiveness in the labor market (81\%). Among the main directions for the development and improvement of the educational brand, the interviewed NUPh employees noted the constant improvement of the quality of educational services (91\% of the respondents), the intensification of international cooperation (86\%), the active involvement of practitioners and scientists in the scientific, volunteer and cultural life of the institution (79\%).

Conclusions. It has been proven that an important component of the brand of a higher education institution is an educational service; image of educational services; the benefits to be provided by the brand owner to consumers of educational services. The most significant factors of popularity and positive attitude towards NUPh and the advantages received by graduates after graduation have been established. A conclusion was made about the high level of corporate culture in HEI, the important elements of which are the presence of the NUPh development strategy, the introduction of effective management technologies and the creation of conditions for the self-realization of employees

Keywords: brand, formation, assessment, results, factors of influence, institution of higher education, public

\author{
How to cite: \\ 4852.2021.248050 \\ (C) The Author(s) 2021 \\ This is an open access article under the Creative Commons CC BY license hydrate
}

Kotvitska, A., Volkova, A., Yakovlieva, O. (2021). Results of public assessment of influence factors on the formation of the brand of the institution of higher education in the pharmaceutical direction. ScienceRise: Pharmaceutical Science, 6 (34), 66-74. doi: http://doi.org/10.15587/2519-

\section{Introduction}

Changes in the economic environment lead to the need for professional reorientation of professionals at different stages of their careers, as well as the development of new areas of professional activity. Such changes are characteristic of the educational process itself and occur under the influence of various factors that affect the economy of individual regions, countries and the world as a whole. Therefore, with the development of globalization of the economy and business, higher education institutions (HEIs) face new goals, namely: training highly qualified professionals capable of working effectively in changing market conditions. This necessitates the active use of modern tools of marketing activities, namely, branding that affects the consumer, as well as his emotions, commitment to the product or service and loyalty [1].

\section{HEI brand:}

- is one of the important criteria for the choice of place of study by entrants and (or) their parents, especially if other conditions of choice are determined to be equal;

- allows you to form a personal brand for higher education both in the learning process (among students of other institutions) and after graduation (in the employment process);

- provides information on the quality of education or the level of competencies of the graduate;

- allows HEI to apply for a certain level of funding, as well as support from the state;

- HEI provides a relationship with the environment, allows you to form a socially responsible image of an innovative institution that operates for the benefit of society $[2,3]$. 
Today, a significant number of scientific papers are devoted to the study of general provisions of branding, its essence, functions and tasks [4], brand management [5], the study of emotional aspects of consumer relations with brands $[6,7]$, customer loyalty to the organization's brand $[8,9]$, approaches to attracting customers through brands [10,11], factors influencing the attitude to the company and the intention to make a purchase $[12,13]$ and aspects of the impact of advertising on brand loyalty [14]. Regarding higher education institutions, scientific works include such aspects as the application of branding in the activities of educational institutions were studied [15, 16], approaches to brand formation of higher education institutions [3] and management models [2, 17], expectations of students who will receive education in a higher education institution that has its own brand, [18] and studying the impact of events on the formation of the brand of a higher education institution [19].

Based on the study of literature sources, it was found that the issues of assessing the public attitude to the brand of the institution was not given enough attention.

Based on the study of literature sources, it was found that the assessment of public attitude to the HEI brand was not given enough attention, and the above research is devoted to some problems of brand formation in educational institutions.

In this regard, the aim of the article is to study the public attitude to the HEI brand, taking into account the specifics of its educational services and the specifics of the market of educational services.

\section{Research planning (methodology)}

When considering the HEI brand in the education market, it is necessary to consider its impact on different audiences.

The object of the study is the target audience of the National University of Pharmacy (NUPh), which is currently one of the most powerful HEIs in pharmaceuticals and the only pharmaceutical educational institution in Ukraine that provides relevant educational services for pharmacists not only in Ukraine, but also other countries of the world for several decades [15].

The main task of the work was to study the attitude of target audiences to the HEI brand to further improve the areas of its management, namely, in relation to:

- popularity of NUPh;
- benefits that graduates have after graduating from the prestigious HEI;

- elements of corporate culture that have a significant impact on the brand and its promotion;

- efficiency of external and internal communications in the institution.

To achieve the goal and objectives of the study, we have developed a research algorithm that consists of 5 stages (Fig. 1).

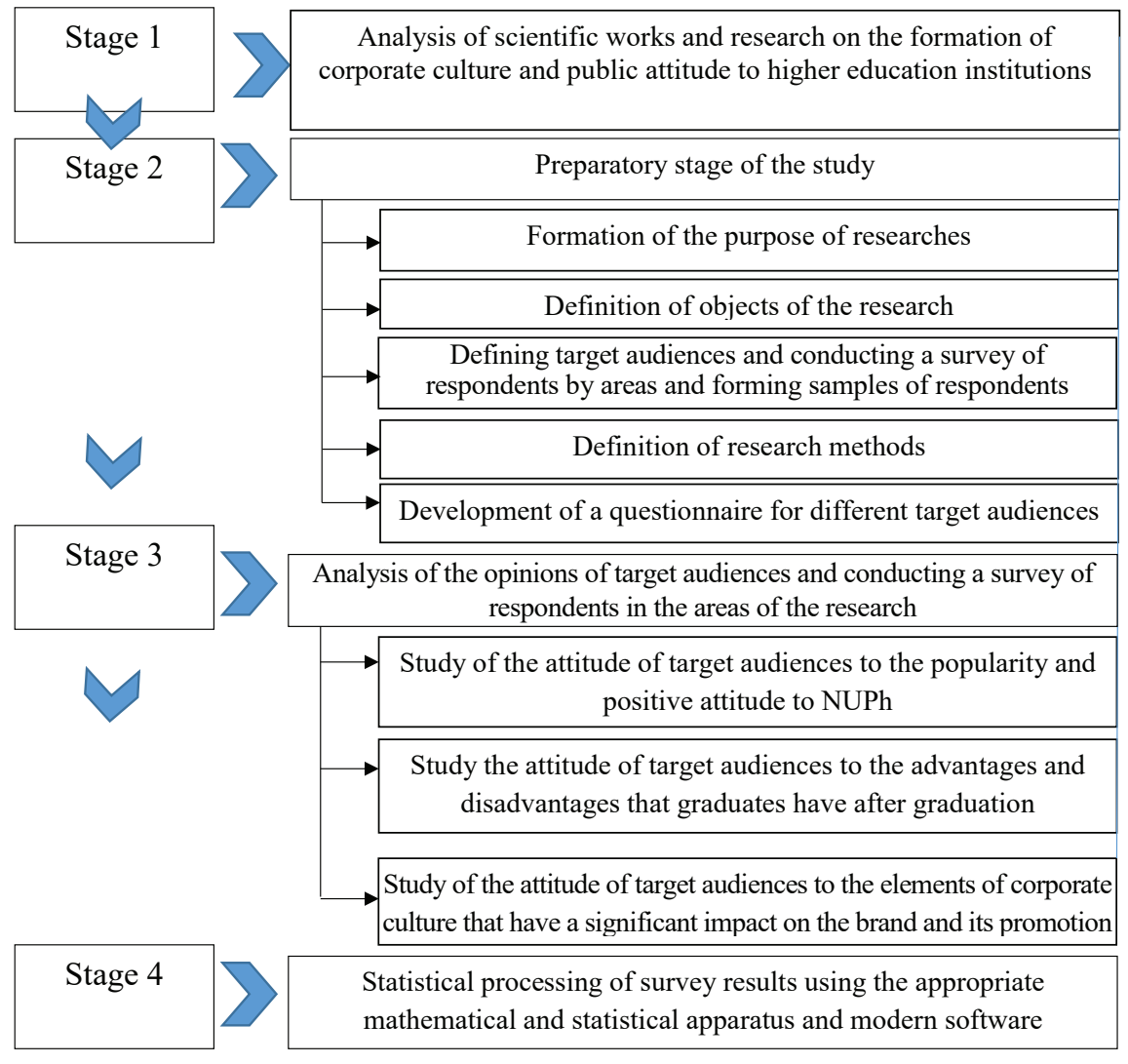

Stage 5

Systematization and analysis of the results of the survey and the formation of directions for the development and improvement of the educational brand and the effectiveness of its external and internal communications

Fig. 1. Algorithm for conducting research on the attitude of target audiences to the HEI brand

\section{Materials and methods}

Research methods: theoretical (analysis and synthesis of scientific literature and normative sources, generalization, analytical, comparative and logical); empirical (description, comparison, questionnaire, mathematical and statistical).

Materials: questionnaires of respondents, which were applicants for higher education and graduates (as consumers of educational services), employees of NUPh (as providers of educational services) and entrants (students and school leavers) (as potential consumers of educational services).

In total, during the 2019-2020 academic year, 2,315 people were interviewed by random sampling, including: 320 applicants for higher education, 125 employees of NUPh, 1,550 entrants, 320 graduates. The choice 
of respondents and the definition of research problems is due to the fact that our view, this approach allows us to get a better idea of studying the attitude of target audiences to the NUPh brand on a wide range of problems of institution development.

Questionnaires were developed for all groups of respondents, which, in addition to information about the respondents, contain a part that defines the purpose of the study, as well as a part with closed, open and combined questions (providing the opportunity to offer their answers).

It should be noted that the questionnaires contain general questions, as well as different ones for all studied categories of respondents. As for the different issues, they are based on the fact that the educational brand exists in two areas, in particular: the brand for entrants, graduates, graduates as consumers of educational services, and the brand for HEI worker, which perceives work in a particular institution as prestigious and desirable.

In order to determine the divergence of respondents' opinions, the concordance coefficient was assessed. If the opinions of experts completely coincide, this coefficient is equal to 1 , otherwise it is equal to 0 . The significance of the concordance coefficient was determined using Pearson's $\chi^{2}$-test, which is compared with tabular data based on the number of degrees of freedom. Given that the $\chi^{2}$-criterion is larger than the tabular value, the agreement of experts is not accidental [20].

For all groups of respondents, the concordance coefficient exceeds 0.75 , which indicates the convergence of respondents' opinions. Pearson's $\chi^{2}$ test exceeds the tabular value, i.e., the agreement of experts is not accidental.

\section{Research results}

It is determined that the HEI brand is a unique and recognizable system of designations, which includes the name of the institution, graphic image (logo), sound symbols and attributes (Brand Attributes), i.e., "functional or emotional associations assigned to this brand by consumers of educational services and potential customers. and HEI social partners. Associations can be positive and negative, have different strengths and importance for different segments of the market of educational services" [19].

According to the experience of leading foreign HEI, important components of the brand of the institution are:

- educational service with all its inherent characteristics;

- the reputation of educational services provided by HEI, as a set of characteristics, expectations, associations that are perceived by the consumer of educational services and attributed to them (brand-image);

- benefits to be provided by the brand owner to consumers of educational services and directly related to the HEI mission;

- image of HEI in the perception of the target audience and the public $[3,16]$.

Thus, there is no doubt that in order to improve the position of HEI in the world rankings and improve the effi- ciency of its operation, it is necessary to study the attitude of the target audience and the public to the HEI brand.

To this end, a study was conducted to identify the opinions and associations of the target audience related to the perception of the brand of the institution and its most important attributes.

At the first stage of the study of the attitude of the target audience to the HEI brand, the factors that determine the popularity and positive attitude to the institution were studied. At this sub-stage of the study, the study of the opinions of two categories of respondents higher education and NUPh staff.

According to seekers for higher education, the most important factor is the positive feedback about the institution (14\% of respondents). The second place is occupied by high quality educational services and the involvement of well-known scientists and practitioners (12\% each factor). The presence of scientific schools, the presence of traditions and active participation of the institution in public life take third place (11\% each factor).

$9 \%$ of respondents consider the use of advertising is important. Also, important, according to higher education seekers, was the provision of HEI with modern classrooms, library, dormitories, etc. $(8 \%)$. Relatively small value for higher education seekers has the history of establishment of the institution and its state status (6\% each factor).

The distribution of respondents' opinions on the popularity and positive attitude to NUPh is presented in Fig. 2.

It should be noted that the widespread use of advertising, according to respondents, indicates the high importance of the institution's communication policy, active use of advertising activities, PR and other methods of promotion not only for successful sales of educational services, but also for forming a positive image.

According to NUPh staff who participated in the survey, all the studied factors are approximately equal in importance and range from $8 \%$ to $12 \%$. However, such factors as the state status of the institution and its material and technical base, respondents identify as the most important factors (12\%).

The second place in importance is occupied by positive feedback from employers about graduates of the institution, the time of the institution, the presence of scientific schools, the presence of traditions and active participation of the institution in public life (10\%).

Regarding the importance of widespread use of advertising to promote educational services provided by NUPh, its importance was noted by $10 \%$ of respondents. The high quality of educational services and the involvement of well-known scientists and practitioners as factors influencing the attitude to NUPh, noted $8 \%$ of respondents.

The distribution of respondents' opinions on the popularity and positive attitude to NUPh is presented in Fig. 3.

The entrants' answers to a similar question were distributed somewhat differently. Thus, in their opinion, the most important factors are the state status of HEI, positive feedback about the institution and the high quality of educational services (13\% each factor). $11 \%$ of respondents noted the material and technical base of the institution and participation in public life. 


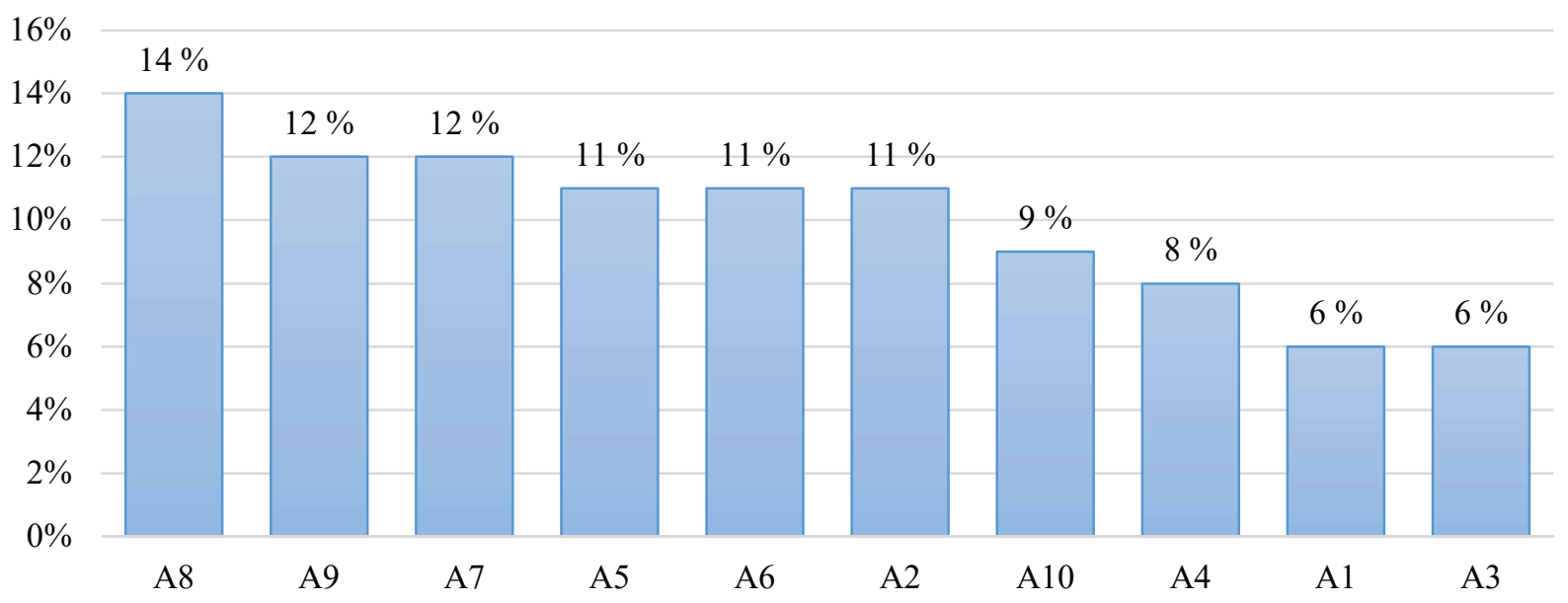

Fig. 2. Distribution of opinions of the surveyed applicants on higher popularity and positive attitude to NUPh: A1 the history of HEI, A2 - the presence of traditions, A3 - state status, A4 - material and technical base (classrooms,

dormitory, classrooms equipped with modern equipment, etc.) , A5 - the presence of scientific schools, A6 participation in public life, A7 - the involvement of famous scientists and practitioners, A8 - positive feedback from employers about graduates, A9 - high quality educational services, A10 - the use of advertising

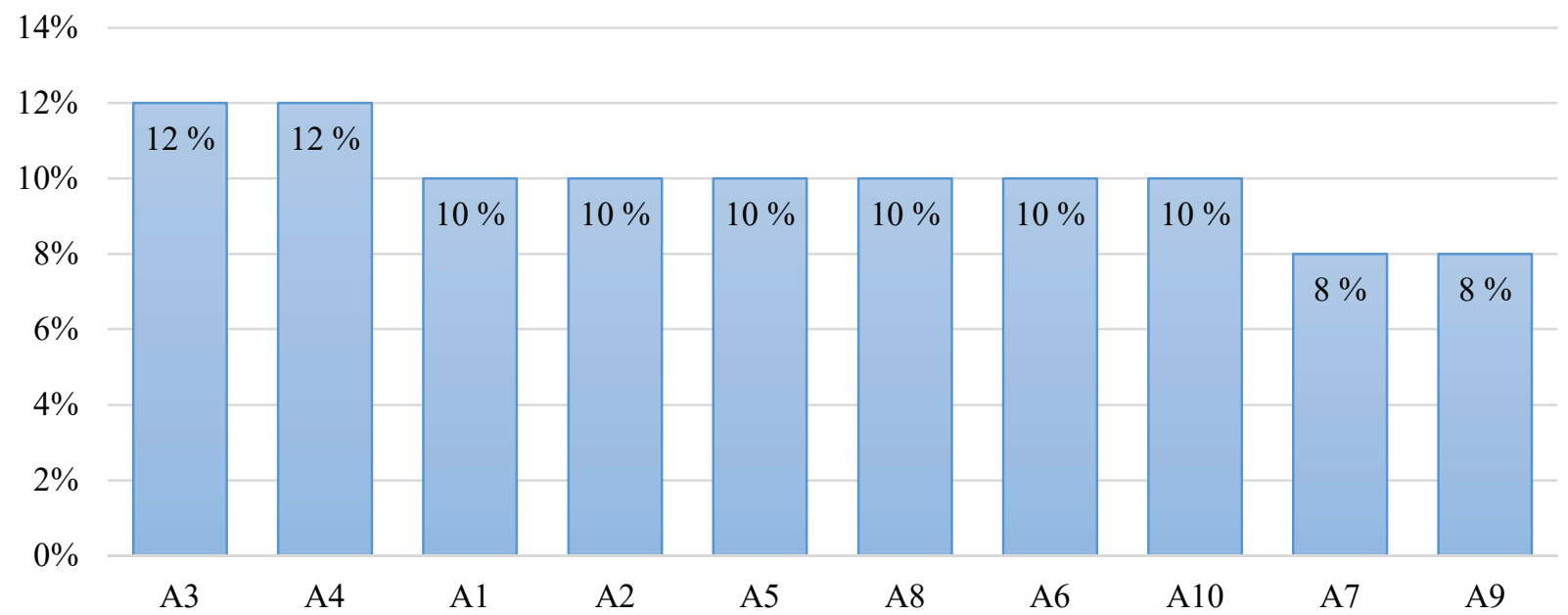

Fig. 3. Distribution of opinions of interviewed employees about the popularity and positive attitude to NUPh: A1 the history of HEI, A2 - the presence of traditions, A3 - state status, A4 - material and technical base (classrooms, dormitory, equipped with modern equipment, etc.), A5 - the presence of scientific schools, A6 - participation in public life, A7 - the involvement of famous scientists and practitioners, A8 - positive feedback from employers about graduates, A9 - high quality educational services, A10 - the use of advertising

The presence of traditions and the time of existence of the institution (10\% each) occupy an important place for entrants. Information about these factors entrants receive when visiting the "Open Days" and from the website of the institution.

Factors such as the availability of science schools and the involvement of well-known scientists and practitioners play a minor role for entrants (6\% each), as a small number of them plan to link their lives with science and have no clear idea of the pharmaceutical education system. Regarding the use of advertising, $7 \%$ of entrants noted its sufficient role.

The distribution of opinions of entrants who participated in the survey is presented in Fig. 4.

In the second sub-stage of the third stage of the study, we studied the opinion of higher education students about studying in an institution with it is own brand.
The questionnaire asked a set of questions about the possibility or impossibility of considering HEI a brand. For example: "What was the main reason for your choice of NUPh?". The survey found that $88 \%$ of higher education respondents surveyed believe that NUPh is a brand, and only $12 \%$ believe that they study at HEI, which is not a brand.

Also, important, in our opinion, is to study the attitude of higher education students to HEI after the first month of study. A set of questions was asked about the attractiveness of classes; learning conditions; living conditions in the dormitory, etc. For example: "What difficulties arose during the period of adaptation to student life?". $86 \%$ of the surveyed applicants for higher education positively characterize their impressions of learning and have no reason to complain. 
At the same time, $14 \%$ of higher education students had a negative impression of NUPh. This is due to difficulties in adapting to student life $(8.8 \%)$ and difficulties in adapting to the study schedule (5\%); complaints about living conditions in the dormitory (3.5\%) and dissatisfaction with the meaningful aspects of education (3\%) (Fig. 5).

After conducting the questionnaire, the main questions of which are presented above, it should be noted that $82.9 \%$ of respondents are satisfied that they have received higher education in NUPh.

Thus, a positive assessment of HEI prevails among $86 \%$ of respondents, with $88 \%$ of respondents surveying higher education believe that NUPh can be called a brand. At the same time, $14 \%$ experience a "gap" between expectations and realities, which suggests that HEIs, which are perceived as brands, have room for improvement.
In the next stage of the study, we studied the opinion of graduates about the benefits they have after graduating from the prestigious HEI.

According to $89 \%$ of respondents, the advantages of prestigious HEI graduates include a high level of theoretical knowledge and practical skills (85\%), a high level of competitiveness in the labour market ( $81 \%$ ), possession of information technology needed to perform professional duties $(80 \%)$, career opportunities $(75 \%)$, employment guarantees (60\%), other (5\%).

The distribution of respondents' opinions on the preferences of graduates of prestigious HEI is presented in Fig. 6.

The next stage of the research was to study the opinion of HEI employees on the influence of the rector's personality on the image of the institution and increase the level of recognition of the HEI brand.

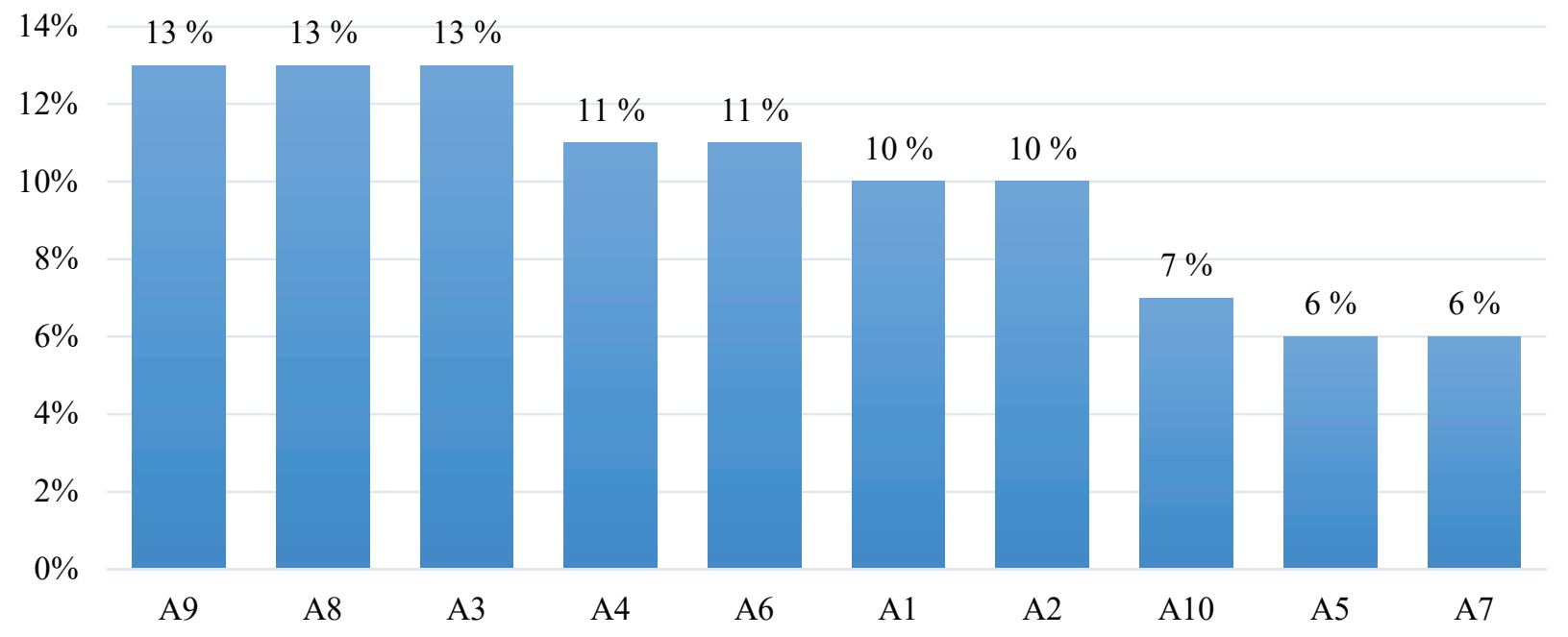

Fig. 4. Distribution of opinions of respondents about the popularity and positive attitude to NUPh: A1 - the history of HEI, A2 - the presence of traditions, A3 - state status, A4 - material and technical base (classrooms, dormitory, equipped classrooms with modern equipment, etc.), A5 - availability of scientific schools, A6 - participation in public life, A7 - involvement of well-known scientists and practitioners, A8 - positive feedback from employers about graduates, A9 - high quality educational services, A10 - use of advertising

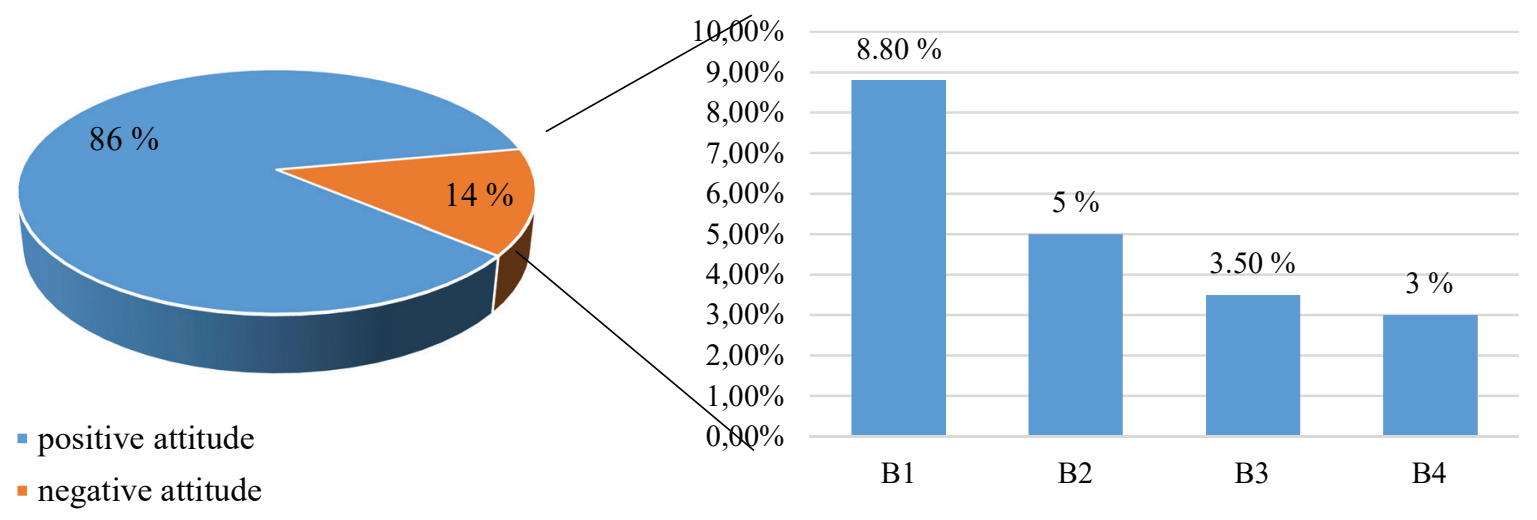

Fig. 5. Distribution of opinions of higher education students on the satisfaction of NUPh after the first month of study: B1 - difficulties in adapting to student life, B2 - difficulties in adapting to the study schedule, B3 - complaints about living conditions in the dormitory, B4 - dissatisfaction with meaningful aspects of learning 
Opinions of the interviewed NUPh employees were distributed almost equally: the rector should be an outstanding scientist $-88 \%$, and a good manager $-85 \%$ of the answers. According to only $4 \%$ of employees, the rector's personality does not affect the brand of the institution, and $2.4 \%$ of employees find it difficult to answer the question (Fig. 7).

There is no doubt that identifying elements of corporate culture that have a significant impact on the brand and its promotion is important enough to improve the HEI brand.

According to NUPh employees, the elements of corporate culture include the following: NUPh development strategy ( $75 \%$ of answers), effective communications ( $74 \%$ of answers), introduction of effective management technologies (69\% of respondents), creation of conditions for self-realization of employees ( $61 \%$ of respondents), ensuring discipline $(56 \%$ of answers), democratic relations with staff and higher education ( $52 \%$ of respondents), collegiality in decision-making ( $43 \%$ of respondents answered), remu- neration (42\% of answers), other ( $9 \%$ of respondents) (Fig. 8).

According to almost all NUPh employees interviewed, building their own brand is impossible without the introduction of innovative teaching methods, elements of dual education, integration of science and education $-96 \%$ of respondents said so. The rest $-4 \%$ of respondents - had difficulties with answering. At the same time, respondents believe that it is necessary to consider the requirements of employers for future professionals - so said $81.6 \%$ of respondents.

Also among the main areas that contribute to the development and improvement of the educational brand, according to NUPh staff, is the continuous improvement of the quality of educational services $-91 \%$ believe, intensification of international cooperation $-86 \%$, active involvement in scientific, volunteer and cultural life and researchers $(79 \%)$ and applicants for higher education $(73 \%)$, building relationships with employers $-62 \%$, intensifying the use of channels for disseminating information about the institution(60\%)andevents that takeplaceinit(58\%) (Fig. 9).

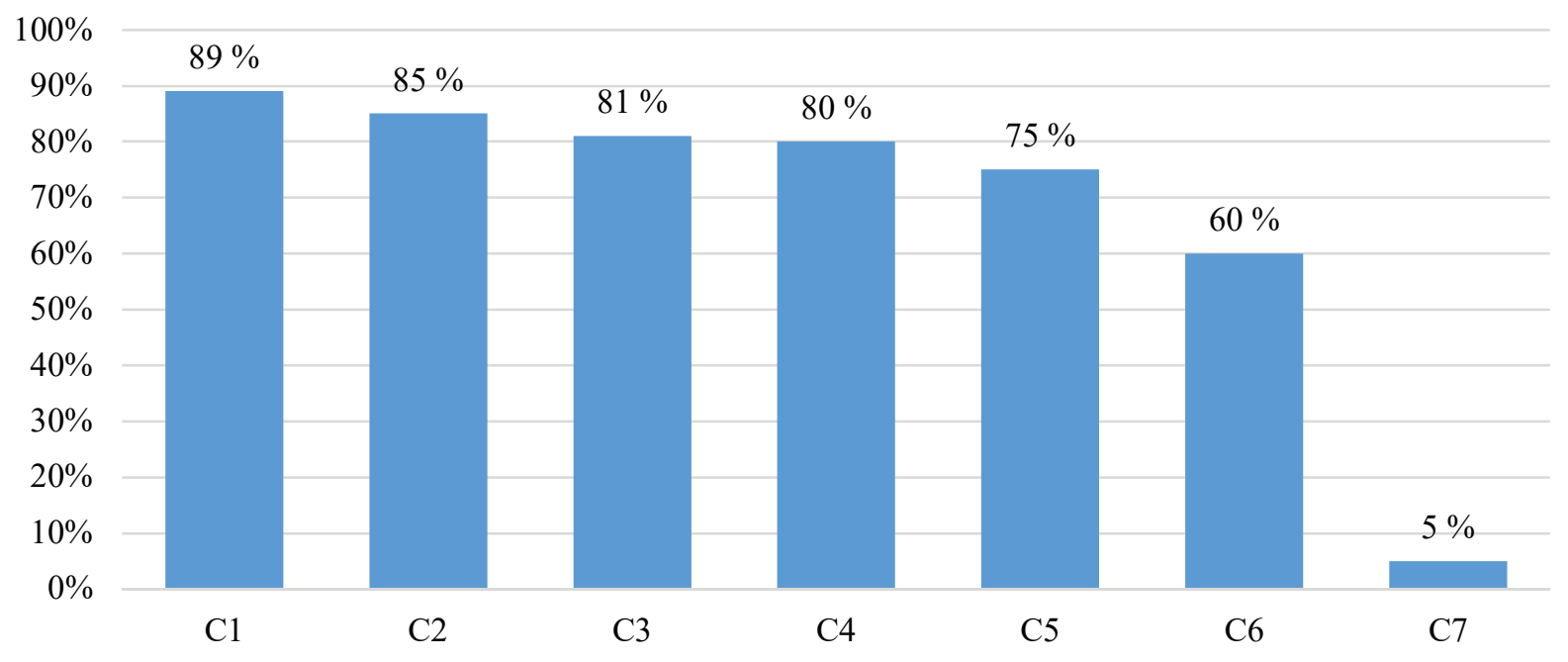

Fig. 6. Advantages of prestigious HEI graduates: $\mathrm{C} 1$ - high level of theoretical knowledge, $\mathrm{C} 2$ - practical skills, $\mathrm{C} 3$ - high level of competitiveness in the labour market, C4 - possession of information technology needed to perform professional duties, C5 - career opportunities, C6 - employment guarantees, C7 - other

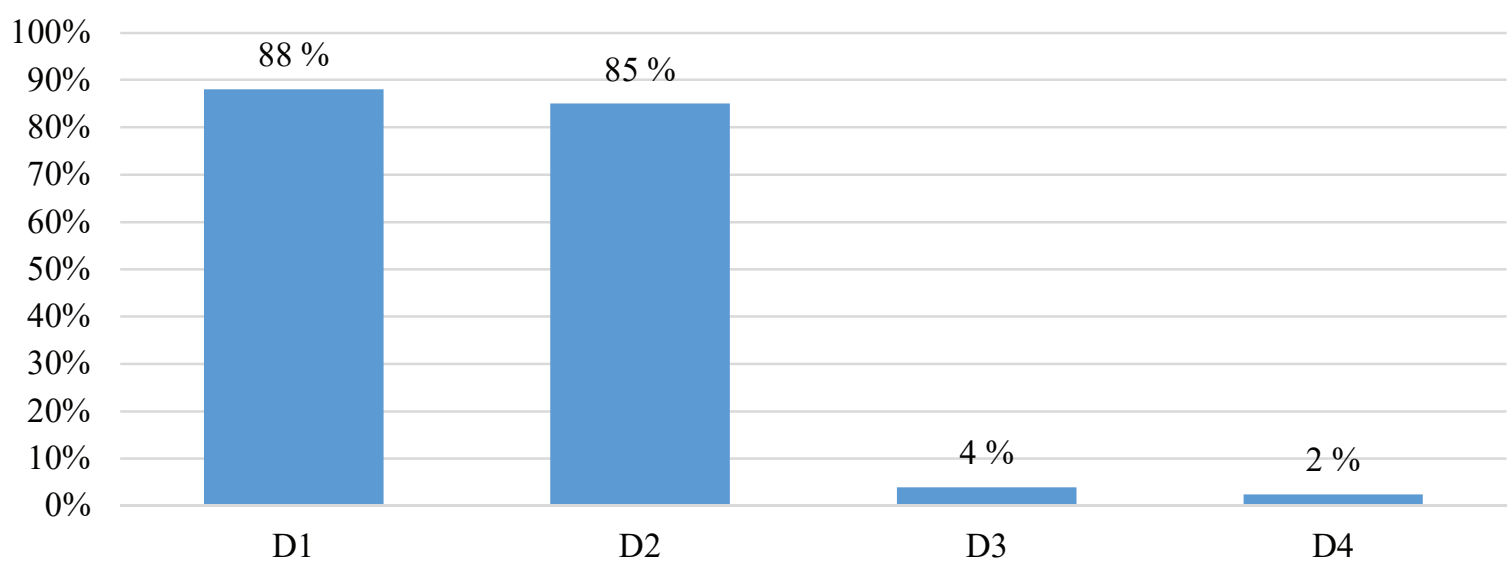

Fig. 7. The influence of the rector's personality on the reputation of NUPh and raising the level of HEI brand awareness: D1 - the rector must be an outstanding scientist, D2 - the rector must be a good manager, D3 - the rector's personality does not affect the brand, D4 - difficult to answer questions 


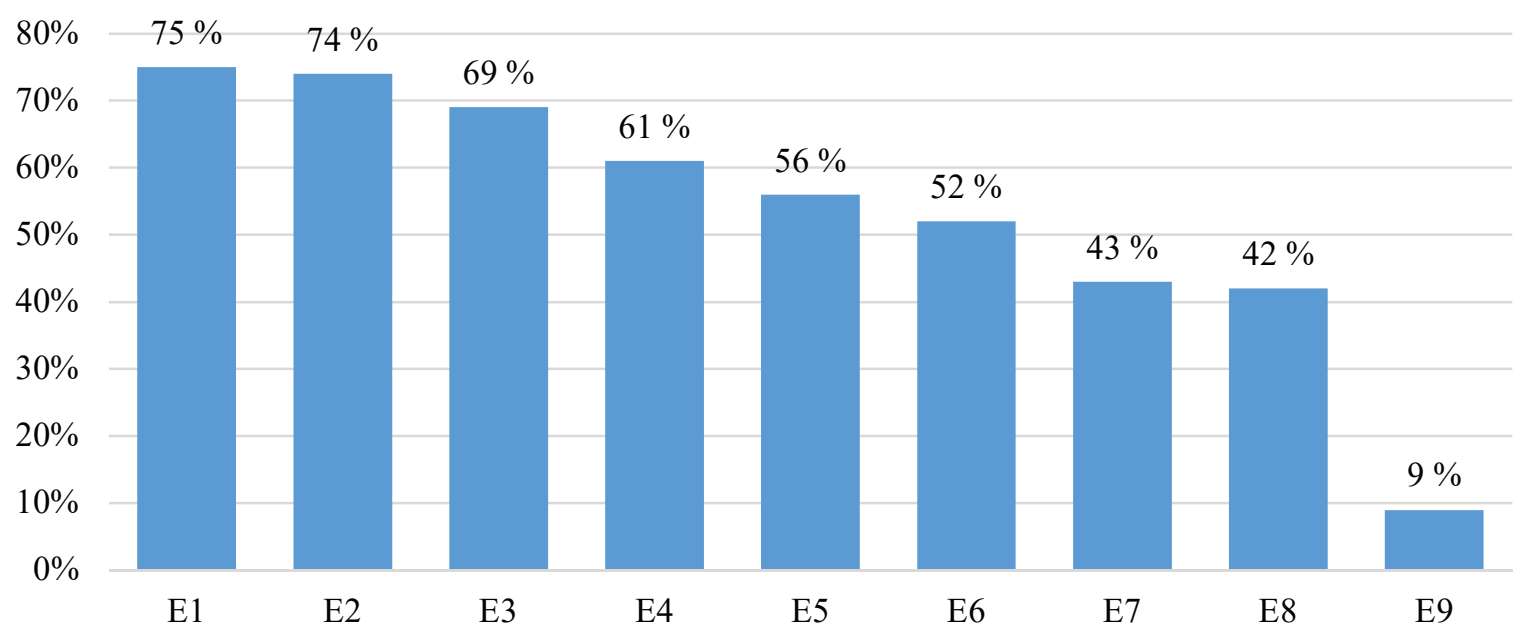

Fig. 8. Distribution of elements of corporate culture that affect the reputation of NUPh and increase the level of HEI brand awareness: E1 - availability of NUPh development strategy, E2 - availability of effective communications, E3 - introduction of effective management technologies, E4 - creating conditions for self-realization, E5 - providing disciplines, E6 - democratic relations with the staff and students of higher education, E7 - collegiality in decisionmaking, E8 - remuneration, E9 - other

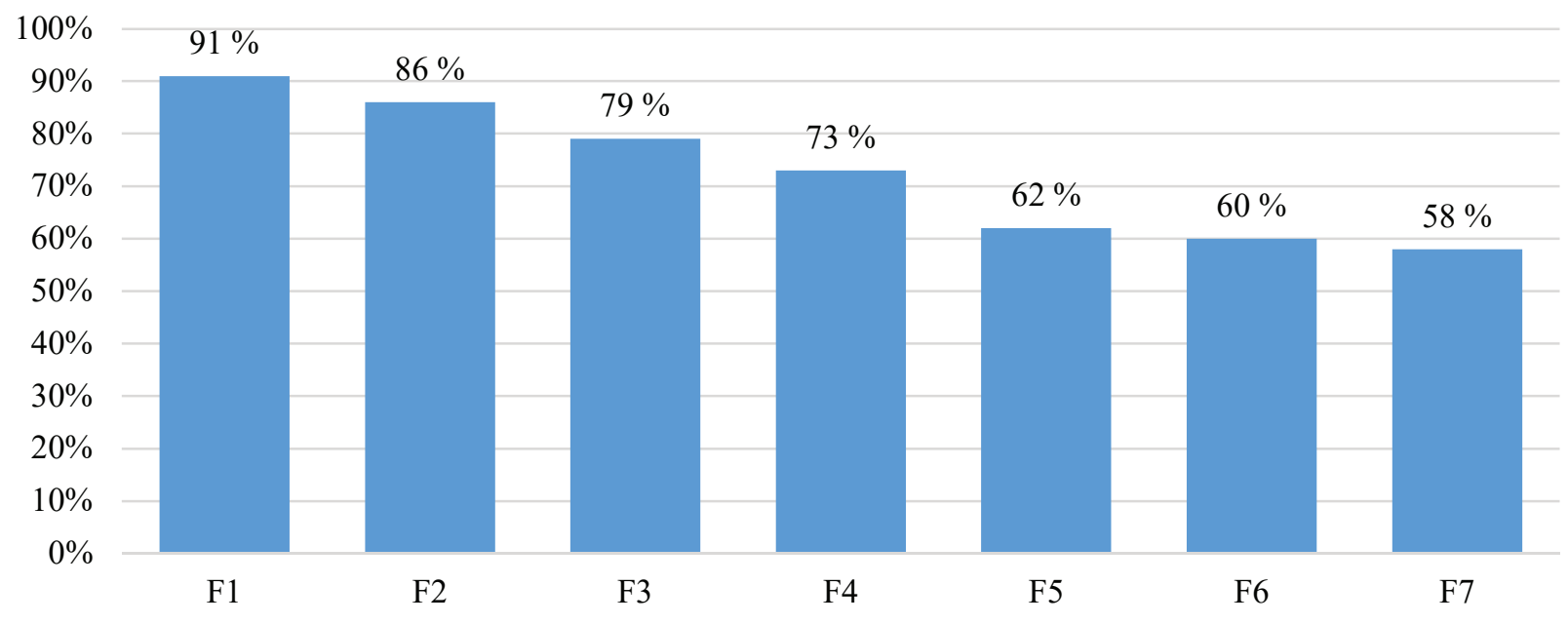

Fig. 9. The main directions of promoting the development and improvement of the educational brand: F1 - continuous improvement of educational services, F2 - intensification of international cooperation, F3 - active involvement of practitioners and scientists, F4 - active involvement of higher education in scientific, volunteer and cultural life, F5 building relations with employers, F6 - intensifying the use of channels for dissemination of information about the institution, F7 - events that take place in it

\section{Discussion of research results}

From the generalized results of the survey of all categories of respondents it can be concluded that the main factors of popularity and positive attitude to NUPh are the positive shouts of employers about graduates, the presence of traditions and participation in public life.

$88 \%$ of surveyed applicants for higher education are convinced that NUPh has an educational brand. Also, the applicants expressed a positive opinion about the institution after the first month of study and $86 \%$ of the surveyed applicants for higher education have no reason to complain.

Graduates mentioned following advantages after graduating from the prestigious HEI - a high level of theoretical knowledge (89\%) and practical skills (85\%), a high level of competitiveness in the labour market (81\%), high skills of information technology needed to perform professional responsibilities $(80 \%)$, career opportunities (75\%), employment guarantees $(60 \%)$, other (5\%).

According to NUPh employees, the main elements of corporate culture include the existence of NUPh development strategy ( $75 \%$ of responses), effective communication (74 \% of responses) and the introduction of effective management technologies (69\% of respondents). Also, $91 \%$ of employees surveyed said that the rector of the institution should be an outstanding scientist and a good manager ( $88 \%$ and $85 \%$ of answers, respectively).

Comparing the results, it is worth noting that scientists consider the status of the institution (public or private) to be a priority factor in the popularity and positive attitude towards HEI. Thus, according to the results presented in the research $[14,21]$, it is noted that prefer- 
ence is given to public higher education institutions, the prestige of the diploma (51\% of higher education students in the first year), affordability (32), further employment $(28 \%)$ and ease of learning prospects $(23 \%)$.

Regarding the perception of the HEI brand by entrants, researchers [9] note that the factors of choosing an educational institution that are important for entrants include prospects for future employment (35\% of respondents), affordability (32\%), self-realization (29\%) and prestige diploma $(25 \%)$.

The main directions of promoting the development and improvement of the educational brand are identified, which are based on the constant improvement of the quality of educational services; intensification of international cooperation; active involvement in the scientific, volunteer and cultural life of the institution of practitioners and scientists and applicants for higher education; intensifying the use of channels for disseminating information about NUPh, etc.

Study limitations are due to the fact that the vast majority of respondents were related to or had information about NUPh.

Prospects for further research should be the development of effective marketing communications to promote the brand of educational services in the market, including abroad, as well as the development of an appropriate program and set of measures to involve entrants, employers and other stakeholder groups in this process.

\section{Conclusions}

1. It is proved that important components of the brand of the institution are educational services with all its inherent characteristics; image of educational services; the benefits that the brand owner will provide to consumers of educational services and are directly related to the mission of HEI, as well as the reputation of HEI in the perception of the target audience and the public.

2 . The study of the attitude of the target audience to the HEI brand allowed us to conclude that:

- regarding the popularity and positive attitude to NUPh, the most important factors, according to applicants for higher education, are positive feedback about the institution, high quality educational services and the involvement of well-known scientists and practitioners; according to NUPh employees who took part in the survey - the state status of the institution and its material and technical base; according to the entrants - the state status of HEI, positive feedback about the institution and the high quality of educational services; the influence of the rector's personality on the reputation of HEI is highly appreciated;

- in terms of the benefits that graduates have after graduating from the prestigious HEI, the most important are theoretical knowledge and practical skills, as well as competitiveness in the labour market and mastery of information technology needed to perform professional duties;

- regarding the elements of corporate culture that have a significant impact on the brand and its promotion, it is important to have a strategy for the development of NUPh, the introduction of effective management technologies and create conditions for self-realization of employees.

3. According to the analysis of the results of the survey, proposed areas that promote the development and improvement of the educational brand. Among them: constant improvement of the quality of educational services due to the introduction of modern teaching methods, the use of dual education, involvement of specialists in the educational process, etc.; intensification of international cooperation (exchange of research and teaching staff, graduate students, graduates, joint research, etc.); building relations with employers, intensifying the use of channels for disseminating information about the institution and events that take place in it, improving marketing communications in promoting the brand of educational services in the market.

\section{Conflict of interests}

The authors declare that they have no conflicts of interest.

\section{Financing}

The study was performed without financial support.

\section{References}

1. Organisation for economic cooperation and development. Statistics and publications. Available at: www.oecd.org Last accessed: 26.03.2021

2. Melewar, T. C., Nguyen, B. (2014). Five areas to advance branding theory and practice. Journal of Brand Management, 21 (9), 758-769. doi: http://doi.org/10.1057/bm.2014.31

3. Zamerchenko, N. I. (2012). Branding in Education. IAroslavskii pedagogicheskii vestnik, 2 (2), 79-81.

4. Fernandes, T., Moreira, M. (2019). Consumer brand engagement, satisfaction and brand loyalty: a comparative study between functional and emotional brand relationships. Journal of Product \& Brand Management, 28 (2), 274-286. doi: http://doi.org/10.1108/ jpbm-08-2017-1545

5. Vera, J. (2016). Two paths to customer loyalty: the moderating effect of the differentiation level strategy in the performance-satisfaction-value-intentions relationship. Journal of Product \& Brand Management, 25 (2), 171-183. doi: http://doi.org/10.1108/ jpbm-01-2015-0789

6. Mills, A. J., Robson, K. (2019). Brand management in the era of fake news: narrative response as a strategy to insulate brand value. Journal of Product \& Brand Management, 29 (2), 159-167. doi: http://doi.org/10.1108/jpbm-12-2018-2150

7. Zhadko, E. A., Kapustina, L. M., Romanova, N. Iu. (2016). Pozitsionirovanie i brending obrazovatelnoi organizatsii. Ekaterinburg: Izd-vo Ural. gos. ekon. un-ta, 204.

8. Wohlfeil, M., Whelan, S. (2012). "Saved!” by Jena Malone: An introspective study of a consumer's fan relationship with a film actress. Journal of Business Research, 65 (4), 511-519. doi: http://doi.org/10.1016/j.jbusres.2011.02.030 
9. Kandampully, J., Zhang, T., Bilgihan, A. (2015). Customer loyalty: a review and future directions with a special focus on the hospitality industry. International Journal of Contemporary Hospitality Management, 27 (3), 379-414. doi: http://doi.org/10.1108/ ijchm-03-2014-0151

10. Maity, M., Gupta, S. (2016). Mediating Effect of Loyalty Program Membership on the Relationship Between Advertising Effectiveness and Brand Loyalty. Journal of Marketing Theory and Practice, 24 (4), 462-481. doi: http://doi.org/10.1080/ 10696679.2016.1205450

11. Garipağaoğlu, B. Ç. (2015). Branding in Higher Education: A Case Study from Turkey. Higher Education Policy, 29 (2), 254-271. doi: http://doi.org/10.1057/hep.2015.24

12. Alikperov, I. M., Zhadko, E. A., Timokhina, G. S. (2016). Model upravleniia brendom obrazovatelnoi organizatsii. Ekonomika i predprinimatelstvo, 11, 474-477.

13. Hwang, J., Kandampully, J. (2012). The role of emotional aspects in younger consumer-brand relationships. Journal of Product \& Brand Management, 21 (2), 98-108. doi: http://doi.org/10.1108/10610421211215517

14. Kotvitska, A. A., Yakovlieva, O. Y. (2021). The study of the theoretical approaches to the event management in order to form the brand of a higher education institution. Social Pharmacy in Health Care, 7 (2), 4-9. doi: http://doi.org/10.24959/sphhcj.21.225

15. National University of Pharmacy. Available at: https://nuph.edu.ua/

16. Gong, T. (2017). Customer brand engagement behavior in online brand communities. Journal of Services Marketing, 32 (3), 286-299. doi: http://doi.org/10.1108/jsm-08-2016-0293

17. Bakasova, O. A. (2016). The impact of social expectations of students with regard to the university brand on de-velopment of academic motivation. Business. Education. Law. Bulletin of Volgograd Business Institute, 1 (34), 264-268.

18. Hollebeek, L. D., Glynn, M. S., Brodie, R. J. (2014). Consumer Brand Engagement in Social Media: Conceptualization, Scale Development and Validation. Journal of Interactive Marketing, 28 (2), 149-165. doi: http://doi.org/10.1016/j.intmar.2013.12.002

19. Alikperov, I. M., Zhadko, E. A., Timokhina, G. S. (2016). Model upravleniia brendom obrazovatelnoi organizatsii. Ekonomika i predprinimatelstvo, 11-2 (76-2), 474-477.

20. Dudarev, O. K., Kustitskaia, T. A., Ovchinnikova, E. V. (2016). Matematicheskaia statistika. Krasnoiarsk, 156.

21. Chang, C.-T., Chu, X.-Y., Tsai, I.-T. (2020). How Cause Marketing Campaign Factors Affect Attitudes and Purchase Intention. Journal of Advertising Research, 61 (1), 58-77. doi: http://doi.org/10.2501/jar-2019-046

Received date 18.08.2021

Accepted date 15.12.2021

Published date 30.12.2021

Alla Kotvitska, Doctor of Pharmaceutical Sciences, Professor, Rector, National University of Pharmacy, Pushkinska str., 53, Kharkiv, Ukraine, 61002

Alina Volkova, $\mathrm{PhD}$, Associated Professor, Department of Social Pharmacy, National University of Pharmacy, Pushkinska str., 53, Kharkiv, Ukraine, 61002

Olena Yakovlieva, Rector's Assistant, National University of Pharmacy, Pushkinska str., 53, Kharkiv, Ukraine, 61002

*Corresponding author: Olena Yakovlieva, e-mail: jakovlevaolena@gmail.com 